\title{
Prognostic value of growth differentiation factor-15 in Chinese patients with heart failure: A prospective observational study
}

\author{
Hua Wang ${ }^{1 *}$, Qingyong Chen ${ }^{1,2 *}$, Yingying Li $^{1}$, Xianchao Jing ${ }^{2}$, Jiefu Yang ${ }^{1,2}$ \\ ${ }^{1}$ Department of Cardiology, Beijing Hospital, Peking University, Beijing, China \\ ${ }^{2}$ Department of Cardiology, West China Hospital, Sichuan University, Chengdu, China
}

\begin{abstract}
Background: Growth differentiation factor-15 (GDF-15), a biomarker associated with remodeling, oxidative stress and inflammation, has been used to stratify heart failure (HF) patients. However, its prognostic value in Chinese HF patients is still unknown.

Methods: GDF-15 levels were examined on admission in 272 consecutive HF patients in Beijing Hospital (a Chinese tertiary medical center) by a commercial enzyme-linked immunosorbent assay. We recorded the incidence of all-cause mortality and/or readmission for $H F$ during a median follow-up period of 558 days. Patients were stratified according to the tertiles of GDF-15.

Results: Fifty-three (19.5\%) patients died and 103 (37.9\%) patients had major adverse cardiac events (MACE) which included the composite outcome of all-cause mortality or readmission for HF at the end of follow-up. Kaplan-Meier survival curves showed that the third tertile of GDF-15 was associated with increased rate of all-cause mortality (compared with the first and second tertiles, $\log$ rank $p=0.001$ and 0.001, respectively) or MACE (compared with the first and second tertiles, $\log$ rank $p=0.002$ and $p<0.001$, respectively). In addition, multivariate Cox regression model showed that the highest tertile of GDF-15 was independently associated with increased risk of all-cause death (hazard ratio $=5.95$, 95\% confidence interval $1.88-18.78, p=0.002)$ compared with the lowest tertile after adjustment for related clinical variables such as age, renal function or $N$-terminal pro-B-type natriuretic peptide.

Conclusions: Plasma GDF-15 is an independent predictor of all-cause mortality in Chinese patients with HF. It may potentially be used to stratify and prognosticate HF patients. (Cardiol J 2018; 25, 2: 245-253) Key words: growth differentiation factor-15, heart failure, remodeling, biomarker, prognosis
\end{abstract}

\section{Introduction}

Heart failure (HF) is a complex syndrome resulted from any structural or functional abnormality that leads to the failure of heart to pump enough blood to the targeted tissues [1, 2]. Approximately 4 million people in China [3] have clinically symptomatic HF. The prognosis in patients with advanced $\mathrm{HF}$ is poor, with mortality rate of
$75 \%$ at 1 year and virtually no survival at 2 years [4]. Thus, early risk stratification in patents with $\mathrm{HF}$ is important for optimizing clinical decisions about treatment and management of end-of-life care. In the past few decades, lots of circulating biomarkers, such as N-terminal pro-B-type natriuretic peptide (NT-proBNP) [5], uric acid [6], galectin-3 [7], etc., had been used to stratify and prognosticate patients with HF [8], among which

Address for correspondence: Jiefu Yang, MD, PhD, Department of Cardiology, Beijing Hospital, Peking University, Beijing, China, tel: +86 13601292259; fax: +86 02885422343, e-mail: yangjiefu2014@sina.com

Received: 06.03.2016 Accepted: 06.08.2016

*Hua Wang and Qingyong Chen contributed equally to this work. 
growth differentiation factor-15 (GDF-15) was extensively studied [9].

Growth differentiation factor-15, a member of transforming growth factor- $\beta$ cytokine superfamily with a molecular weight of about $28 \mathrm{kDa}$ [10], was increasingly expressed in the pathological situations associated with inflammation, reactive oxygen species and cardiac remodeling, and thus might contribute to progression of HF $[11,12]$.

In the last decades, lots of studies indicated that elevation of plasma GDF-15 levels could suggest poor prognosis in several cardiovascular diseases, such as acute myocardial infarction [13-15], atrial fibrillation [16], and diabetic cardiomyopathy $[9,17]$. Kempf et al. [13] confirmed that GDF-15 was an independent predictor of mortality for Caucasian population with chronic HF. However, the prognostic utility of GDF-15 in Chinese HF patients was unclear and the related data were deficient. In this study, we evaluated the prognostic value of the plasma GDF-15 levels on admission in Chinese HF patients.

\section{Methods}

\section{Study population and design}

Two hundred seventy-two consecutive patients with an established final diagnosis of $\mathrm{HF}$ who were admitted to the Department of Cardiology of Beijing Hospital (a tertiary educational hospital affiliated to National Health and Family Planning Commission, Beijing, China) were prospectively enrolled from June 2012 to March 2015. Diagnosis was established according to the current guidelines for the management of $\mathrm{HF}[1,2]$. In this study, the patients were robustly divided into two categories: $\mathrm{HF}$ with preserved ejection fraction (HFpEF) category including those with left ventricular ejection fraction (LVEF) higher than $45 \%$ or HF with reduced ejection fraction ( $\mathrm{HFrEF}$ ) category for those with LVEF of $45 \%$ or less $[18,19]$.

We collected the blood samples of each patient the next morning after admission to hospital and recorded the related baseline clinical characteristics and in-hospital events. Echocardiography was done in echo room of Being Hospital. Standard guidelinedirected medical therapy and optimal management were provided according to the latest guidelines for the management of HF, unless contraindications.

\section{Inclusion and exclusion criteria}

Inpatients definitely diagnosed with $\mathrm{HF}$ aged more than 18 years were enrolled regardless of etiology. The exclusion criteria were: known or newly diagnosed malignancy, severe non-cardiac comorbidities that would affect the prognosis and patient's disagreement to participate in the study.

\section{Laboratory analyses}

Growth differentiation factor-15 concentration was determined by the enzyme-linked immunosorbent assay (ELISA) with a commercial human GDF-15 ELISA kits (R\&D systems, Minnesota, USA) according to the instructions of the manufacturer. Routine assays of some other biochemical parameters, such as hemoglobin, albumin, creatinine, uric acid, cardiac enzyme profiles, and NT-proBNP, etc., were performed in the clinical laboratory of Beijing Hospital. We employed a simplified Modification of Diet in Renal Disease equation to calculate the estimated glomerular filtration rate (eGFR) by the equation: eGFR = $186.8 \times$ plasma creatinine $e^{-1.154} \times$ age $^{-0.203}(\times 0.742$ if female patients) [20, 21].

\section{Follow-up and MACE}

Patients were subsequently followed up by telephone or at the outpatient clinic of Beijing Hospital. The primary endpoint was all-cause mortality and the secondary composite endpoint of major adverse cardiac events (MACE) included all-cause mortality and readmission for HF.

\section{Ethical approval}

This study was approved by the Ethics Committee of Being Hospital. Written informed consent was obtained from each included patient.

\section{Statistical analysis}

Normally distributed data were presented as the mean \pm standard deviation (SD); whereas non-normally distributed data were presented as the median (interquartile range [IQR]). Categorical data were expressed as percentages. Continuous data with normal distribution and homogeneity of variance were compared by one-way ANOVA or by Kruskal-Wallis test. Categorical data were compared by $\chi^{2}$ analysis. Spearman rank correlation was used to explore the relationship between GDF-15 tertiles and related clinical parameters. Logistic regression analyses were done to examine associations between variables and all-cause mortality. Receiver operating characteristic curve (ROC) was performed to statistically assess the sensitivity and specificity of GDF-15 measurement and its prognostic utility. Cox regression analysis was used to identify predictors of all-cause mortality. Kaplan-Meier survival curves and the log-rank test were done according to 


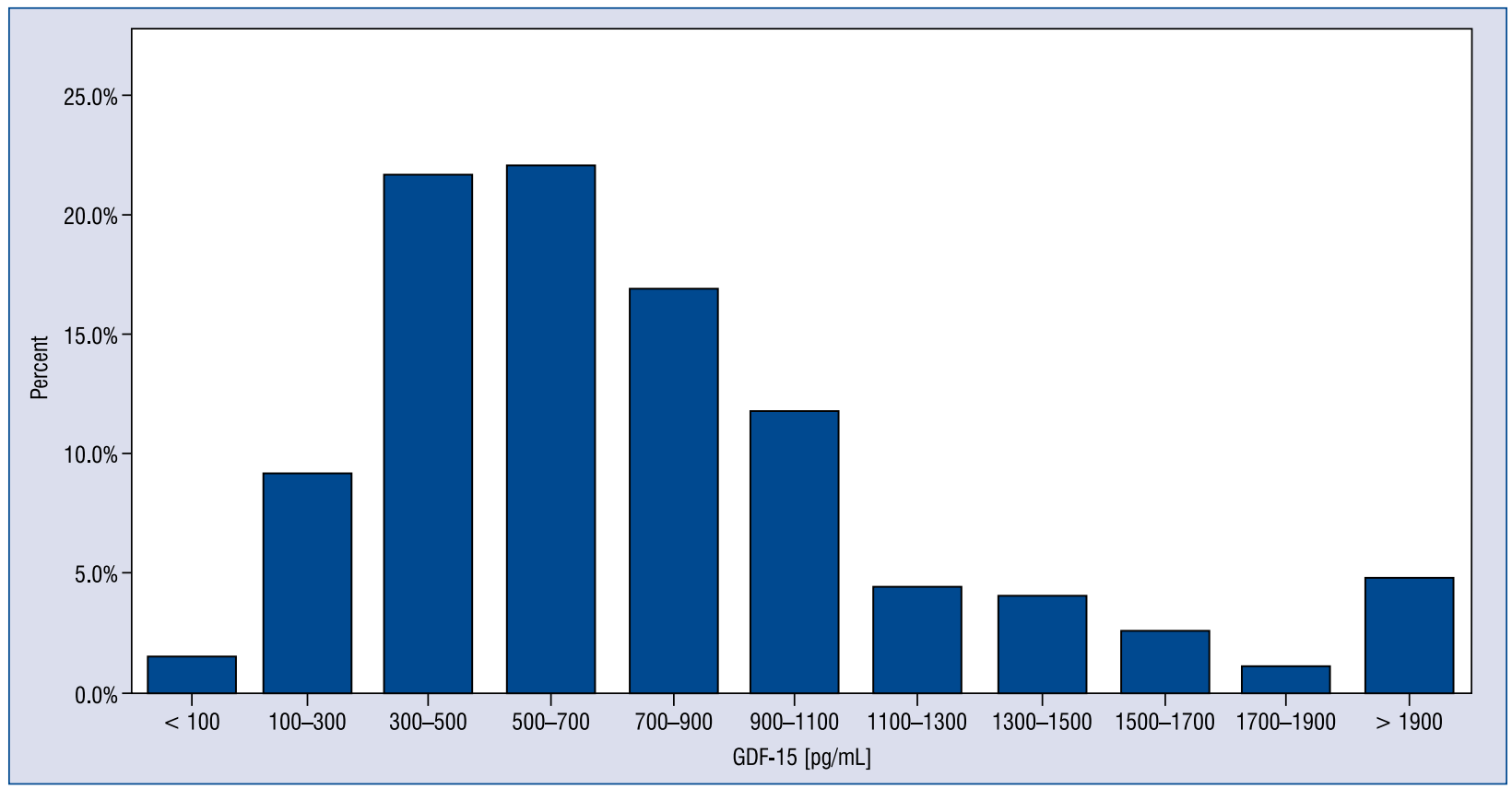

Figure 1. The distribution of baseline growth differentiation factor-15 (GDF-15) levels in this study ( $n=272$ ). Median (interquartile range): 646.75 (412.48-968.03) pg/mL.

the time of the MACE. All statistical analyses were performed by SPSS version 18.0 (SPSS Inc, Chicago, Illinois). Differences were considered significant at $\mathrm{p}$ values $<0.05$ (two-sided).

\section{Results}

\section{Baseline clinical characteristics of patients}

Overall $272 \mathrm{HF}$ patients with a median age of 77 years, of whom $44.1 \%$ (120) were female, were included in the study. Echocardiographic examination was performed in $98.5 \%$ (268) of patients, of whom, $47 \%$ (126) were categorized as HFrEF and 53\% (142) as HFpEF. For patients received guideline-directed medical therapy; $58.1 \%$ patients were prescribed angiotensin converting enzyme inhibitor (ACEI) or angiotensin receptor blocker (ARB), $64.6 \%$ spironolactone, and $79.1 \%$ beta-blocker.

The median concentration of GDF-15 was $646.75 \mathrm{ng} / \mathrm{mL}$, with an IQR from $412.48 \mathrm{pg} / \mathrm{mL}$ to $968.03 \mathrm{pg} / \mathrm{mL}$. The patients were stratified into tertiles according to GDF-15 concentrations (cutoff limits $511.35 \mathrm{ng} / \mathrm{mL}$ and $839.09 \mathrm{ng} / \mathrm{mL}$ ): the first tertile included values below $511.35 \mathrm{ng} / \mathrm{mL}$; the second tertile - from $511.36 \mathrm{ng} / \mathrm{mL}$ to 839.09 $\mathrm{ng} / \mathrm{mL}$; the third tertile - above $839.10 \mathrm{ng} / \mathrm{mL}$.

Figure 1 shows that the distribution of GDF-15 concentration is right-skewed. No significant differ- ence in GDF-15 concentration was found between HFrEF subgroup and HFpEF subgroup $(p=0.09)$.

Patients with higher GDF-15 levels were characterized by more advanced age ( 78 years for $2^{\text {nd }}$ tertile and $3^{\text {rd }}$ tertile vs. 72 years for $1^{\text {st }}$ tertile) and longer hospital stay (the mean duration of hospital stay was 12 days for $3^{\text {rd }}$ tertile, 11 for $2^{\text {nd }}$ tertile and 10 for $3^{\text {rd }}$ tertile). The occurrence of coronary artery disease (CAD; 70 patients, $77.8 \%$ ) and diabetes mellitus (DM; 46 patients, $51.1 \%$ ) was more frequent in the second tertile of GDF-15. Other previously diagnosed conditions including hypertension, obesity, dyslipidemia, chronical obstructive pulmonary disease, peripheral arterial disease, atrial fibrillation, smoking, and alcohol consumption showed no statistically significant difference between GDF-15 tertiles (all $\mathrm{p}$ values $>0.05$, Table 1). Spearman's rank test showed that the correlations with age $(r=0.27, p<0.001)$ and length of stay in hospital $(r=0.18, p=0.004)$ were very weak. No statistically significant correlations were found between GDF-15 levels and occurrence of CAD ( $p=0.18)$ or diabetes mellitus $(p=0.54)$.

The frequency of use of beta-blocker, mineralocorticoid receptor antagonists, diuretics and digitalis was similar between different GDF-15 tertiles except that patients in lower tertiles were treated with more ACEI or ARB; a weak negative correlation was found between use of ACEI or ARB and GDF-15 levels $(\mathrm{r}=-0.25, \mathrm{p}<0.001)$. 
Table 1. Baseline clinical characteristics by tertiles of GDF-15 levels.

\begin{tabular}{|c|c|c|c|c|}
\hline & $\begin{array}{l}\text { Low GDF-15 } \\
\text { tertile (n = 91) }\end{array}$ & $\begin{array}{l}\text { Middle GDF-15 } \\
\text { tertile }(\mathrm{n}=91)\end{array}$ & $\begin{array}{l}\text { High GDF-15 } \\
\text { tertile }(n=90)\end{array}$ & $\mathbf{P}$ \\
\hline GDF-15 range $[\mathrm{pg} / \mathrm{mL}]$ & $\leq 511.35$ & 511.36-839.09 & $\geq 839.10$ & - \\
\hline GDF-15 [pg/mL] & $352.4(264.4-414.0)$ & $647.1(574.4-743.4)$ & 968.0 (1144.6-1551.4) & - \\
\hline \multicolumn{5}{|l|}{ Demographics } \\
\hline Age [years] & 72 (59-79) & $78(73-82)$ & $78(71-82)$ & $<0.01^{*}$ \\
\hline Male & $55(60.4 \%)$ & $45(49.5 \%)$ & $52(57.8 \%)$ & 0.30 \\
\hline BMI $\left[\mathrm{kg} / \mathrm{m}^{2}\right]$ & $25.56 \pm 4.19$ & $25.66 \pm 4.69$ & $24.3 \pm 4.36$ & 0.09 \\
\hline \multicolumn{5}{|l|}{ History } \\
\hline Hypertension & $63(70 \%)$ & $74(82.2 \%)$ & $65(72.2 \%)$ & 0.13 \\
\hline Diabetes mellitus & $26(28.9 \%)$ & $46(51.1 \%)$ & $30(33.3 \%)$ & $0.005^{*}$ \\
\hline Obesity & $11(12.9 \%)$ & $15(17.2 \%)$ & $9(10.7 \%)$ & 0.45 \\
\hline Dyslipidemia & $64(71.1 \%)$ & $56(62.2 \%)$ & $50(56.2 \%)$ & 0.11 \\
\hline CAD & $44(48.9 \%)$ & $70(77.8 \%)$ & $50(55.6 \%)$ & $<0.01 *$ \\
\hline COPD & $7(7.8 \%)$ & $9(10 \%)$ & $11(12.2 \%)$ & 0.61 \\
\hline PAD & $6(6.7 \%)$ & $9(10 \%)$ & $13(14.4 \%)$ & 0.18 \\
\hline Atrial fibrillation & $41(45.6 \%)$ & $35(38.9 \%)$ & $48(53.3 \%)$ & 0.15 \\
\hline Smoking & $34(39.5 \%)$ & $32(37.6 \%)$ & $39(43.3 \%)$ & 0.74 \\
\hline Alcohol & $17(19.5 \%)$ & $15(17.6 \%)$ & $11(12.2 \%)$ & 0.39 \\
\hline Length of stay [days] & $10(7-13.25)$ & $11(7.25-16)$ & $12(9-18)$ & $0.02 *$ \\
\hline \multicolumn{5}{|l|}{ Medications } \\
\hline ACEI or ARB & $65(73 \%)$ & $54(60.7 \%)$ & $50(56.2 \%)$ & $<0.01^{*}$ \\
\hline MRA & $61(68.5)$ & $56(62.9 \%)$ & $39(43.3 \%)$ & 0.63 \\
\hline Beta-blocker & $71(79.8 \%)$ & $74(83.1 \%)$ & $67(74.4 \%)$ & 0.35 \\
\hline Diuretics & $65(73 \%)$ & $74(81.3 \%)$ & $75(83.3 \%)$ & 0.15 \\
\hline Digitalis & $17(19.1 \%)$ & $16(18 \%)$ & $18(20.0 \%)$ & 0.94 \\
\hline \multicolumn{5}{|l|}{ Laboratory parameters } \\
\hline Creatinine $[\mu \mathrm{mol} / \mathrm{L}]$ & $78(67-89.75)$ & 91 (79-111.75) & 106 (87-148) & $<0.01^{*}$ \\
\hline eGFR $\left[\mathrm{mL} / \mathrm{min} / 1.73 \mathrm{~m}^{2}\right]$ & 84.5 (70.7-103.3) & $64.4(50.2-80.3)$ & $49.5(37.0-73.1)$ & $<0.01 *$ \\
\hline Uric acid $[\mu \mathrm{mol} / L]$ & $366.72 \pm 136.83$ & $423.07 \pm 109.4$ & $471.11 \pm 200.39$ & $<0.01^{*}$ \\
\hline Glucose [mmol/L] & $5.4(4.93-5.98)$ & $5.5(4.9-6.75)$ & $5.7(4.8-7.8)$ & 0.39 \\
\hline Albumin $[\mathrm{g} / \mathrm{L}]$ & $41(39-42)$ & $39(37-41)$ & $38(34-40)$ & $<0.01^{*}$ \\
\hline Hemoglobin [g/L] & $134.98 \pm 23.11$ & $122.08 \pm 16.54$ & $117.86 \pm 25.09$ & $<0.01^{*}$ \\
\hline cTnl [ng/mL] & $0.02(0.01-0.1)$ & $0.04(0.01-0.13)$ & $0.08(0.03-0.5)$ & $0.01^{*}$ \\
\hline NT-proBNP [pg/mL] & 1234 (496.7-2439.5) & 1775.5 (937.79-3781.75) & 3685 (1691-10796) & $<0.01^{*}$ \\
\hline \multicolumn{5}{|l|}{ Cardiac function } \\
\hline NYHA III-IV & $59(67.8 \%)$ & $78(91.8 \%)$ & $72(88.9 \%)$ & $<0.01^{*}$ \\
\hline LVEF [\%] & $40(28-60)$ & $55(35-60)$ & $53(34-60)$ & 0.11 \\
\hline HFpEF & $39(43.3 \%)$ & $53(58.9 \%)$ & $50(56.8 \%)$ & 0.08 \\
\hline HFrEF & $51(56.7 \%)$ & $37(41.1 \%)$ & $38(43.2 \%)$ & 0.08 \\
\hline
\end{tabular}

*Significant difference. Data are presented as median (interquartile range) or mean \pm standard difference according to respective distribution type and categorized data are presented as number (percentage); GDF-15 - growth differentiation factor-15; BMI — body mass index; CAD coronary artery disease; COPD — chronic obstructive pulmonary disease; PAD — peripheral arterial disease; ACEI — angiotensin converting enzyme inhibitor; ARB - angiotensin receptor blocker; MRA - mineralocorticoid receptor antagonist; eGFR - estimated glomerular filtration rate; cTnl - cardiac troponin I; NT-proBNP - N-terminal pro-B-type natriuretic peptide; NYHA - New York Heart Association; LVEF — left ventricular ejection fraction; HFpEF — heart failure with preserved ejection fraction; HFrEF — heart failure with reduced ejection fraction

Higher tertile of GDF-15 was associated with more severe renal function impairment (higher creatinine, higher uric acid level and lower eGFR), worse cardiac function (higher NT-proBNP and higher proportion of New York Heart Association [NYHA] III-IV) and more severe myocardial injury 
Table 2. Outcomes according to tertiles of growth differentiation factor-15 (GDF-15).

\begin{tabular}{lcccc}
\hline & $\begin{array}{c}\text { Low GDF-15 } \\
\text { tertile }(\mathbf{n}=91)\end{array}$ & $\begin{array}{c}\text { Middle GDF-15 } \\
\text { tertile }(\mathbf{n}=91)\end{array}$ & $\begin{array}{c}\text { High GDF-15 } \\
\text { tertile }(\mathbf{n}=90)\end{array}$ & P \\
\hline All-cause death & $4(4.4 \%)$ & $16(17.6 \%)$ & $33(36.7 \%)$ & $<0.001^{*}$ \\
MACE & $15(16.5 \%)$ & $35(38.5 \%)$ & $53(58.9 \%)$ & $<0.001^{*}$ \\
Readmission for HF & $11(12.1 \%)$ & $24(26.4 \%)$ & $34(37.8 \%)$ & $<0.001^{*}$ \\
\hline
\end{tabular}

*Statistically significant difference; Major adverse cardiac events (MACE) included the composite outcome of all-cause mortality and/or readmission for heart failure (HF)

(cardiac troponin I [cTnI]), whereas albumin and hemoglobin concentrations were slightly lower; blood glucose, high sensitivity $\mathrm{C}$ reactive protein (hsCRP) and LVEF were similar (Table 1). The correlations between GDF-15 levels and creatinine $(\mathrm{r}=0.45, \mathrm{p}<0.001)$, eGFR $(\mathrm{r}=-0.46$, $\mathrm{p}<0.001)$, NT-proBNP $(\mathrm{r}=0.40, \mathrm{p}<0.001)$ or albumin $(\mathrm{r}=-0.41, \mathrm{p}<0.001)$ were moderate; the correlations between GDF-15 and uric acid $(\mathrm{r}=0.24, \mathrm{p}<0.001)$ or hemoglobin $(\mathrm{r}=-0.31$, $\mathrm{p}<0.001)$ were weak; no significant correlation was shown between GDF-15 and hsCRP ( $p=0.96)$.

For cTnI, a biomarker of myocardial injury, a significant positive correlation was found between GDF-15 tertiles and cTnI $(r=0.26, p<0.001)$, with the median (IQR) concentration of $0.02(0.01-$ $-0.1) \mathrm{ng} / \mathrm{mL}, 0.04(0.01-0.13) \mathrm{ng} / \mathrm{mL}$ and 0.08 $(0.03-0.5) \mathrm{ng} / \mathrm{mL}$ for the $1^{\text {st }}$ tertile, $2^{\text {nd }}$ tertile and $3^{\text {rd }}$ tertile of GDF-15, respectively.

For LVEF, no significant difference $(\mathrm{p}=0.11)$ was found between different tertiles of GDF-15; for the $1^{\text {st }}$ tertile, $2^{\text {nd }}$ tertile and $3^{\text {rd }}$ tertile, the median (IQR) was 40\% (28-60\%), 55\% (35-60\%) and 53\% (34-60\%), respectively. The Spearman's rank correlation analysis showed that there was no significant correlation between tertiles of GDF-15 and LVEF values $(\mathrm{r}=0.08, \mathrm{p}=0.178)$. Thus, in this population with HF, GDF-15 could provide additional prognostic information independent of LVEF values.

The proportions of patients with NYHA III-IV in the $1^{\text {st }}$ tertile, $2^{\text {nd }}$ tertile and $3^{\text {rd }}$ tertile of GDF-15 were $67.8 \%$ (59), $91.8 \%$ (78) and $88.9 \%$ (72), respectively. Although, higher tertiles of GDF-15 were associated with a higher proportion of NYHA III-IV, no significant correlation $(\mathrm{p}=0.125)$ between these parameters was found.

\section{Follow-up data and MACE}

A total of 24 (8.8\%) patients were lost to followup with the median follow-up time of 558 days. The primary endpoint occurred in $19.5 \%$ (53 patients) and the secondary endpoint occurred in $37.9 \%$ (103 patients). The outcomes by different GDF-15 tertiles were summarized in Table 2. Patients in the third GDF-15 tertile had higher incidence of all-cause mortality and/or MACE compared with the lower tertiles. The concentration of GDF-15 in patients with MACE was higher than in those without MACE; the medians (IQR) were 858.62 (636.6-1269.91) pg/mL and 557.48 (361.0-816.97) $\mathrm{pg} / \mathrm{mL}$, respectively, with $\mathrm{p}<0.001$. Also, the level of GDF-15 in patients with all-cause mortality was higher than in those who survived; the medians (IQR) were $986.55(747.68-1493.57) \mathrm{pg} / \mathrm{mL}$ and 577.25 (381.35-846.31) pg/mL, respectively, with $\mathrm{p}<0.001$.

\section{Prognostic significance of GDF-15}

Kaplan-Meier survival analysis showed that the higher tertile of GDF-15 was associated with incremental rate of primary endpoint (compared with middle and low tertiles of GDF-15, the log rank $\mathrm{p}=0.001$ and $\mathrm{p}=0.001$, respectively, Fig. 2A) and secondary endpoint (compared with middle and low tertiles of GDF-15, the log rank $\mathrm{p}=0.002$ and $\mathrm{p}<0.001$, respectively, Fig. 2B).

The incidence of primary and secondary endpoints also increased significantly when compared the middle tertile with the low tertile of GDF-15 (the $\log$ rank $p=0.02$ and $p=0.01$, respectively).

The ability of GDF-15 to discriminate for MACE was evaluated by area under the ROC curve (AUC). The AUC for GDF-15 was 0.724 (95\% confidence interval [CI] 0.662- 0.786, $\mathrm{p}<0.001)$. The largest AUC for GDF-15 was obtained at the optimal cutoff value of $636.24 \mathrm{pg} / \mathrm{mL}$, with the sensitivity of $75.73 \%$, specificity of $65.31 \%$, and Youden index $=0.39$. The AUC for NT-proBNP was $0.673(95 \%$ CI $0.607-0.740, p=0.00)$. Pairwise comparison of ROC curves between GDF-15 and NT-proBNP revealed that the difference between areas was 0.05 (95\% CI $-0.025-0.125, \mathrm{p}=0.19$, Fig. 3), indicating a trend of superiority of GDF- 15 versus NT-proBNP in predicting the occurrence of MACE for Chinese HF patients. When compared the values of GDF-15 with NT-proBNP in all-cause mortality prediction, we obtained similar results (the AUC for GDF-15 was 0.763, Youden index $=0.478$, 


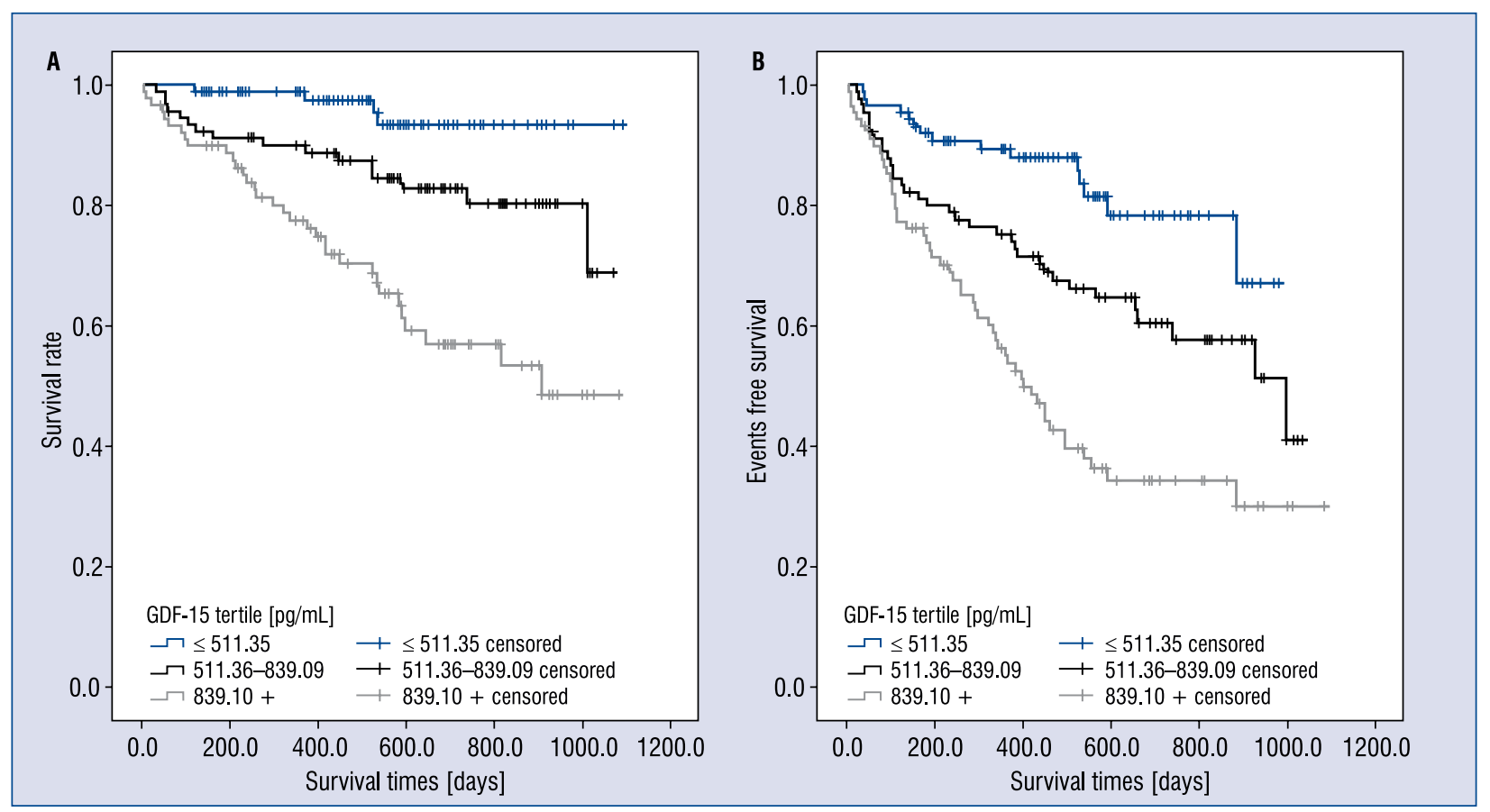

Figure 2. A. Kaplan-Meier survival curves for mortality (primary endpoint) according to growth differentiation factor-15 (GDF-15) tertiles (log rank $p=0.00$ ). A gradual increase in all-cause mortality was shown between GDF-15 tertiles; B. Kaplan-Meier survival curves for mortality and/or readmission for heart failure (major adverse cardiac events [MACE], secondary endpoint) according to GDF-15 tertiles (log rank $p=0.00$ ). A gradual increase in MACE was shown between GDF-15 tertiles.

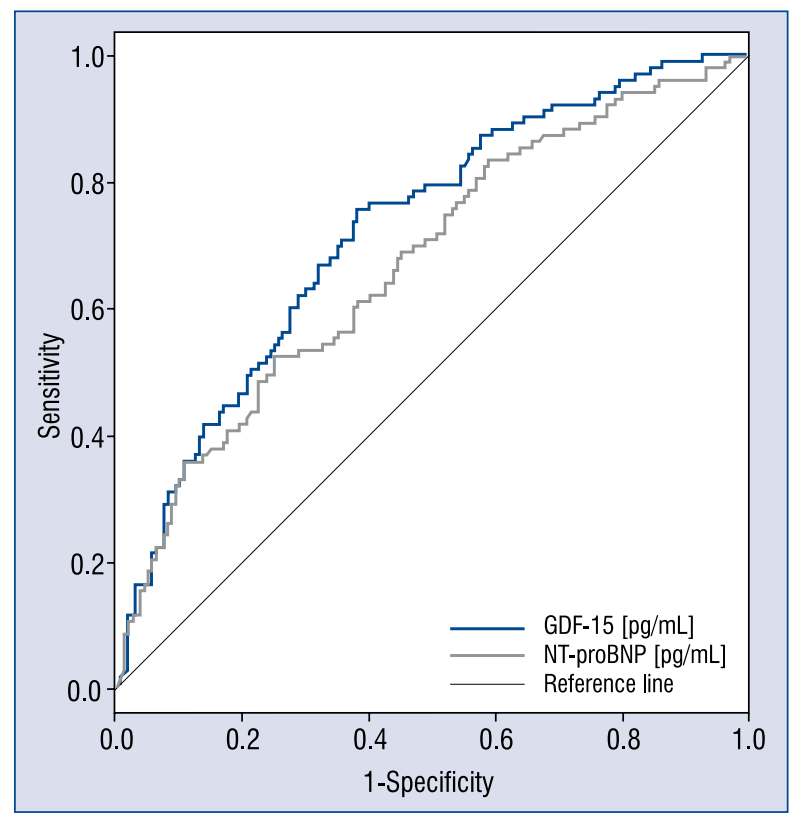

Figure 3. Combined receiver-operating characteristic curves for growth differentiation factor-15 (GDF-15) and $\mathrm{N}$-terminal pro-B-type natriuretic peptide (NT-proBNP) for major adverse cardiac events. Area under the curve for GDF-15 is $0.742(p=0.00)$ and for NT-proBNP is $0.673(p=0.00)$; the difference between areas was 0.05 $(p=0.19)$. sensitivity $=81.13 \%$, specificity $=66.67 \%$, cutoff value $=710.35 \mathrm{pg} / \mathrm{mL}, \mathrm{p}<0.001)$.

We further tested the associations between the related variables that differed significantly between tertiles (Table 1) and the risk of allcause mortality by the univariate Cox regression analysis. Advanced age, longer time of stay in hospital, previous CAD, deteriorated renal function, higher levels of uric acid and NT-proBNP were associated with increased risk of allcause mortality (all p values $<0.05$, Table 3 ). Conversely, higher level of albumin or hemoglobin was associated with decreased risk of allcause mortality (both $\mathrm{p}$ values $<0.05$, Table 3 ). With regard to GDF-15, compared with the first tertile of GDF-15, high tertile of GDF-15 significantly increased the risk of all-cause mortality. The hazard ratios (HRs) for all-cause mortality in patients in the second and third tertiles were 4.64 $(\mathrm{p}=0.008)$ and $12.59(\mathrm{p}<0.001)$, respectively. After including all related variables with $\mathrm{p}<0.05$ in Table 3 into multivariate Cox regression model by forward likelihood ratio (LR) method, we found that the third tertile of GDF-15 was significantly associated with increased risk of all-cause mortality $(\mathrm{HR}=5.95,95 \%$ CI 1.88-18.78, $\mathrm{p}=0.002$, Table 4$)$ 
Table 3. Univariate Cox regression analysis of predictors of all-cause mortality at the end of follow-up.

\begin{tabular}{|c|c|c|}
\hline Variables & HR (95\% CI) & $\mathbf{P}$ \\
\hline Age [years] & 1.07 (1.03-1.11) & $0.001^{*}$ \\
\hline $\begin{array}{l}\text { Length of stay in } \\
\text { hospital [days] }\end{array}$ & $1.04(1.01-1.06)$ & $0.002 *$ \\
\hline Diabetes mellitus & $1.34(0.73-2.46)$ & 0.35 \\
\hline CAD & $2.27(1.15-4.49)$ & $0.02 *$ \\
\hline ACEI or ARB & $0.64(0.35-1.17)$ & 0.15 \\
\hline $\begin{array}{l}\text { Creatinine } \\
{[\mu \mathrm{mol} / \mathrm{L}]}\end{array}$ & 1.008 (1.003-1.014) & $0.002^{*}$ \\
\hline $\begin{array}{l}\text { eGFR }[\mathrm{mL} / \mathrm{min} / \\
\left./ 1.73 \mathrm{~m}^{2}\right]\end{array}$ & $0.98(0.97-0.99)$ & $0.002^{*}$ \\
\hline Uric acid $[\mu \mathrm{mol} / \mathrm{L}]$ & $1.003(1.001-1.005)$ & $0.002^{*}$ \\
\hline Albumin $[g / L]$ & $0.91(0.85-0.98)$ & $0.02^{*}$ \\
\hline Hemoglobin [g/L] & $0.98(0.97-1)$ & $0.01 *$ \\
\hline $\begin{array}{l}\text { NT-proBNP, } \\
\text { per } 500 \mathrm{pg} / \mathrm{mL}\end{array}$ & $1.05(1.02-1.07)$ & $<0.001^{*}$ \\
\hline NYHA III-IV & $2.44(0.83-7.21)$ & 0.11 \\
\hline GDF-15 [pg/mL] & - & $<0.001 *$ \\
\hline First tertile & 1.0 & - \\
\hline Second tertile & 4.64 (1.49-14.48) & $0.008^{*}$ \\
\hline Third tertile & $12.59(4.23-37.46)$ & $<0.001^{*}$ \\
\hline
\end{tabular}

* Statistically significant difference; $\mathrm{Cl}$ - confidence interval; $\mathrm{HR}$ - hazard ratio; other abbreviations as in Table 1

when compared with the first tertile, after adjusting for the other variables. While, the second tertile became non-significant $(\mathrm{HR}=2.54,95 \%$ CI $0.78-8.24, \mathrm{p}=0.12$, Table 4$)$. The creatinine, eGFR, uric acid, albumin, hemoglobin or history of CAD became non-significant in the multivariate Cox regression model. While, age $(\mathrm{HR}=1.04$, $\mathrm{p}=0.002)$, length of stay in hospital $(\mathrm{HR}=1.03$, $\mathrm{p}=0.046$ ), or NT-proBNP(HR per $500 \mathrm{pg} / \mathrm{mL}=1.03$, $\mathrm{p}=0.03$ ) still harbored their prognostic value of all-cause death. Simultaneously, GDF-15 remained significant when it was used as a continues variable. The Hosmer-Lemeshow test indicated satisfactory calibration for this model $(\mathrm{p}=0.86)$.

\section{Discussion}

In present study, we found that elevated levels of plasma GDF-15 increased the risk of all-cause mortality in Chinese HF patients. After adjustment for some other predictors, such as, age, creatinine, uric acid, hemoglobin and NT-proBNP, etc., GDF-15 still exhibited its independent predictive value. Additionally, this study also showed that patients
Table 4. Multivariate Cox regression analysis of predictors of all-cause mortality at the end of follow-up.

\begin{tabular}{lcc}
\hline Variables & HR $(95 \% \mathrm{Cl})$ & P \\
\hline Age [years] & $1.05(1.01-1.10)$ & $0.01^{*}$ \\
Length of stay in & $1.03(1.00-1.05)$ & $0.046^{*}$ \\
hospital [days] & - & 1.0 \\
CAD & - & 0.88 \\
Creatinine & - & \\
[ $\mu$ mol/L] & & 0.90 \\
eGFR $[\mathrm{mL} / \mathrm{min} /$ & - & 0.11 \\
$\left./ 1.73 \mathrm{~m}^{2}\right]$ & - & 0.62 \\
Uric acid $[\mu \mathrm{mol} / \mathrm{L}]$ & - & 0.99 \\
Albumin $[\mathrm{g} / \mathrm{L}]$ & - & $0.03^{*}$ \\
Hemoglobin $[\mathrm{g} / \mathrm{L}]$ & $1.03(1.00-1.05)$ & \\
NT-proBNP, & & $0.003^{*}$ \\
per $500 \mathrm{pg} / \mathrm{mL}$ & - & - \\
GDF-15 [pg/mL] & 1.0 & 0.12 \\
First tertile & $2.54(0.78-8.24)$ & $0.002^{*}$ \\
Second tertile & $5.95(1.88-18.78)$ & \\
Third tertile & &
\end{tabular}

* Statistically significant difference. Age, length of stay in hospital NT-proBNP and GDF-15 were associated with increased risk of all-cause mortality; heart failure from multivariate Cox regression analysis by forward likelihood ratio method. Variables with $p<0.05$ on univariate analysis were shown and included in the multivariable model; $\mathrm{Cl}$ - confidence interval; $\mathrm{HR}$ - hazard ratio; other abbreviations as in Table 1.

who died due to any cause or experienced MACE had higher levels of GDF-15 compared with the events-free counterparts. ROC analysis showed that GDF-15 concentration higher than $636.24 \mathrm{pg} /$ $/ \mathrm{mL}$ was helpful in identifying patients at risk of MACE and GDF-15 level higher than $710.35 \mathrm{pg} /$ $/ \mathrm{mL}$ contributed to predicting all-cause mortality. Therefore, this study confirmed the independent prognostic utility of GDF-15 in Chinese HF patient.

Till now, this conclusion was consistent with some other studies conducted in Caucasian HF population. Valsartan Heart Failure Trial (Val-HeFT) [22] proved that baseline GDF-15 concentration was independently associated with increased risks of all-cause mortality (HR for GDF-15 levels per $100 \mathrm{ng} / \mathrm{L}=1.017)$ and first morbid events $(\mathrm{HR}=$ 1.02) after adjustment for baseline clinical characteristics and related biochemical variables in all HF patients [19]. Kempf et al. [23] also supported that GDF-15 could be utilized as a new biomarker of the risk of mortality in patients with chronic HF which provided prognostic value beyond traditional clinical and biochemical variables [20]. DominguezRodriguez et al. [9] and Foley et al. [24] confirmed 
the role of GDF-15 in predicting morbidity and mortality in diabetic cardiomyopathy patients and in $\mathrm{HF}$ population receiving cardiac synchronization therapy, respectively. However, little data could be acquired in Asian population. In present study, we verified the promising prognostic value of GDF-15 in Chinese HF patients in both univariate and multivariate model.

The plasma GDF-15 levels will be affected by several co-factors. Under normal conditions, GDF-15 is expressed at low levels in almost all tissues. However, in pathological situations, such as HF, myocardial remodeling, oxidative stress or proinflammatory state, GDF-15 expression increases significantly $[12,16,25]$. In our study, GDF-15 was positively correlated with advanced age, deteriorated renal function and increased NT-proBNP or cTnI; whereas it was negatively correlated with albumin or hemoglobin. Those findings indicated that GDF-15 integrated several clinical and biochemical markers to provide a comprehensive prognostic information for HF.

However, it should be pointed out that GDF-15 was not a cardiac-specific biomarker. Besides cardiac myocytes, GDF-15 can also be secreted by macrophages [10], vascular endothelial, smooth muscle cells [26], and adipocytes [27] in response to oxidative stress or chronic inflammation. Just like some other non-cardiac-specific biomarkers, such as hemoglobin, uric acid, or CRP, GDF-15 was also able to provide pathophysiological and prognostic information for patients with HF. Thus, to interpret the value of circulating GDF-15 properly and to get an overall prognostic assessment, GDF-15 levels should be evaluated in conjunction with the cardiac-specific markers, such as NT-proBNP.

There were many limitations of this study. Firstly, the sample size was small and the follow-up time was short. Secondly, GDF-15 was measured only one time on admission; we did not know how it interacted with time and how it fluctuated over time during the progression of HF. Thirdly, we enrolled all types of HF patients including both HFrEF and HFpEF and analyzed data as a homogeneous one, which could garble or dilute the prognostic information of GDF-15, because different subtype of HF might have distinct prognosis. Fourthly, the exactly pathophysiological role of chronic elevation of GDF-15 in HF was still poorly defined and whether GDF-15 could be used as a therapeutic target was yet unknown. Regrettably, this study did not answer the question whether decrease the level of GDF-15 would improve the prognosis of HF. We plan to investigate this issue in subsequent research.

\section{Conclusions}

Plasma GDF-15 is an independent predictor of all-cause mortality in Chinese patients with HF. Evaluation of GDF-15 level contributes to stratify and prognosticate patients with $\mathrm{HF}$ independent of conventional risk factors.

\section{Acknowledgements}

This work is funded by the National Key Technology Support Program of China. The research subject number is BJ-2012-143.

The authors owe gratitude to the colleagues of Department of Cardiology and Clinical Laboratory of Beijing Hospital. Thanks to Tianya Liang and Weimeng Tian for their contribution to the collection and sorting of data during follow-up.

\section{Conflict of interest: None declared}

\section{References}

1. McMurray JJV, Adamopoulos S, Anker SD, et al. ESC Committee for Practice Guidelines. ESC Guidelines for the diagnosis and treatment of acute and chronic heart failure 2012: The Task Force for the Diagnosis and Treatment of Acute and Chronic Heart Failure 2012 of the European Society of Cardiology. Developed in collaboration with the Heart Failure Association (HFA) of the ESC. Eur Heart J. 2012; 33(14): 1787-1847, doi: 10.1093/ eurheartj/ehs104, indexed in Pubmed: 22611136.

2. Yancy CW, Jessup M, Bozkurt B, et al. 2013 ACCF/AHA Guideline for the Management of Heart Failure: A Report of the American College of Cardiology Foundation/American Heart Association Task Force on Practice Guidelines. Circulation. 2013; 128(16): e240-e327, doi: 10.1161/cir.0b013e31829e8776.

3. Zhou J, Cui X, Ge J. [The epidemiological profile of heart failure patients in China]. Zhonghua Xin Xue Guan Bing Za Zhi. 2015; 43(12): 1018-1021, indexed in Pubmed: 26888832.

4. Rose EA, Gelijns AC, Moskowitz AJ, et al. Randomized Evaluation of Mechanical Assistance for the Treatment of Congestive Heart Failure (REMATCH) Study Group. Long-term use of a left ventricular assist device for end-stage heart failure. N Engl J Med. 2001; 345(20): 1435-1443, doi: 10.1056/NEJMoa012175, indexed in Pubmed: 11794191.

5. Tsutamoto T, Wada A, Maeda K, et al. Attenuation of compensation of endogenous cardiac natriuretic peptide system in chronic heart failure: prognostic role of plasma brain natriuretic peptide concentration in patients with chronic symptomatic left ventricular dysfunction. Circulation. 1997; 96(2): 509-516, doi: 10.1161/01.cir.96.2.509, indexed in Pubmed: 9244219.

6. Anker SD, Doehner W, Rauchhaus M, et al. Uric acid and survival in chronic heart failure: validation and application in metabolic, functional, and hemodynamic staging. Circulation. 2003; 107(15): 1991-1997, doi: 10.1161/01.CIR.0000065637.10517.A0, indexed in Pubmed: 12707250.

7. AbouEzzeddine OF, Haines P, Stevens S, et al. Galectin-3 in heart failure with preserved ejection fraction. A RELAX trial substudy (Phosphodiesterase-5 Inhibition to Improve Clinical 
Status and Exercise Capacity in Diastolic Heart Failure). JACC Heart Fail. 2015; 3(3): 245-252, doi: 10.1016/j.jchf.2014.10.009, indexed in Pubmed: 25742762.

8. Gaggin HK, Januzzi JL. Biomarkers and diagnostics in heart failure. Biochim Biophys Acta. 2013; 1832(12): 2442-2450, doi: 10.1016/j.bbadis.2012.12.014, indexed in Pubmed: 23313577.

9. Domínguez-Rodríguez A, Avanzas P, González-González J, et al. Growth Differentiation Factor 15, a New Prognostic Marker in Diabetic Cardiomyopathy. Rev Esp Cardiol (Engl Ed). 2016; 69(1): 81-83, doi: 10.1016/j.rec.2015.09.008, indexed in Pubmed: 26699098.

10. Bootcov MR, Bauskin AR, Valenzuela SM, et al. MIC-1, a novel macrophage inhibitory cytokine, is a divergent member of the TGF-beta superfamily. Proc Natl Acad Sci U S A. 1997; 94(21): 11514-11519, doi: 10.1073/pnas.94.21.11514, indexed in Pubmed: 9326641.

11. Braunwald E. The war against heart failure: the Lancet lecture. Lancet. 2015; 385(9970): 812-824, doi: 10.1016/S01406736(14)61889-4, indexed in Pubmed: 25467564.

12. Wollert KC, Kempf T. Growth differentiation factor 15 in heart failure: an update. Curr Heart Fail Rep. 2012; 9(4): 337-345, doi: 10.1007/s11897-012-0113-9, indexed in Pubmed: 22961192.

13. Kempf T, Björklund E, Olofsson S, et al. Growth-differentiation factor-15 improves risk stratification in ST-segment elevation myocardial infarction. Eur Heart J. 2007; 28(23): 2858-2865, doi: 10.1093/eurheartj/ehm465, indexed in Pubmed: 17977844.

14. Khan SQ, Ng K, Dhillon O, et al. Growth differentiation factor-15 as a prognostic marker in patients with acute myocardial infarction. Eur Heart J. 2009; 30(9): 1057-1065, doi: 10.1093/ eurheartj/ehn600, indexed in Pubmed: 19168526.

15. Minamisawa M, Motoki H, Izawa A, et al. Comparison of Inflammatory Biomarkers in Outpatients With Prior Myocardial Infarction. Int Heart J. 2016; 57(1): 11-17, doi: 10.1536/ihj.15-197, indexed in Pubmed: 26742699.

16. Wallentin L, Hijazi Z, Andersson U, et al. ARISTOTLE Investigators. Growth differentiation factor 15 , a marker of oxidative stress and inflammation, for risk assessment in patients with atrial fibrillation: insights from the Apixaban for Reduction in Stroke and Other Thromboembolic Events in Atrial Fibrillation (ARISTOTLE) trial. Circulation. 2014; 130(21): 1847-1858, doi: 10.1161/CIRCULATIONAHA.114.011204, indexed in Pubmed: 25294786.

17. Dominguez-Rodriguez A, Abreu-Gonzalez P, Avanzas P. Usefulness of growth differentiation factor-15 levels to predict diabetic cardiomyopathy in asymptomatic patients with type 2 diabetes mellitus. Am J Cardiol. 2014; 114(6): 890-894, doi: 10.1016/j. amjcard.2014.06.020, indexed in Pubmed: 25073564.
18. Vasan RS, Levy D. Defining diastolic heart failure: a call for standardized diagnostic criteria. Circulation. 2000; 101(17): 2118-2121, indexed in Pubmed: 10790356.

19. Steinberg BA, Zhao X, Heidenreich PA, et al. Get With the Guidelines Scientific Advisory Committee and Investigators. Trends in patients hospitalized with heart failure and preserved left ventricular ejection fraction: prevalence, therapies, and outcomes. Circulation. 2012; 126(1): 65-75, doi: 10.1161/CIRCULATIONAHA.111.080770, indexed in Pubmed: 22615345.

20. Levey AS, Bosch JP, Lewis JB, et al. A more accurate method to estimate glomerular filtration rate from serum creatinine: a new prediction equation. Modification of Diet in Renal Disease Study Group. Ann Intern Med. 1999; 130(6): 461-470, indexed in Pubmed: 10075613.

21. Manzano-Fernández S, Januzzi JL, Boronat-Garcia $\mathrm{M}$, et al. $\beta$-trace protein and cystatin $\mathrm{C}$ as predictors of long-term outcomes in patients with acute heart failure. J Am Coll Cardiol. 2011; 57(7): 849-858, doi: 10.1016/j.jacc.2010.08.644, indexed in Pubmed: 21310322.

22. Anand IS, Kempf T, Rector TS, et al. Serial measurement of growth-differentiation factor-15 in heart failure: relation to disease severity and prognosis in the Valsartan Heart Failure Trial. Circulation. 2010; 122(14): 1387-1395, doi: 10.1161/CIRCULATIONAHA.109.928846, indexed in Pubmed: 20855664.

23. Kempf T, von Haehling S, Peter T, et al. Prognostic utility of growth differentiation factor-15 in patients with chronic heart failure. J Am Coll Cardiol. 2007; 50(11): 1054-1060, doi: 10.1016/j.jacc.2007.04.091, indexed in Pubmed: 17825714.

24. Foley PWX, Stegemann B, Ng K, et al. Growth differentiation factor-15 predicts mortality and morbidity after cardiac resynchronization therapy. Eur Heart J. 2009; 30(22): 2749-2757, doi: 10.1093/eurheartj/ehp300, indexed in Pubmed: 19666898.

25. Stahrenberg R, Edelmann F, Mende M, et al. The novel biomarker growth differentiation factor 15 in heart failure with normal ejection fraction. Eur J Heart Fail. 2010; 12(12): 1309-1316, doi: 10.1093/eurjhf/hfq151, indexed in Pubmed: 20837635.

26. Nickel N, Jonigk D, Kempf T, et al. GDF-15 is abundantly expressed in plexiform lesions in patients with pulmonary arterial hypertension and affects proliferation and apoptosis of pulmonary endothelial cells. Respir Res. 2011; 12: 62, doi: 10.1186/14659921-12-62, indexed in Pubmed: 21548946.

27. Ding Qi, Mracek T, Gonzalez-Muniesa P, et al. Identification of macrophage inhibitory cytokine-1 in adipose tissue and its secretion as an adipokine by human adipocytes. Endocrinology. 2009; 150(4): 1688-1696, doi: 10.1210/en.2008-0952, indexed in Pubmed: 19074584. 